\title{
El Centro de Investigación y Documentación Musical- Unidad Asociada al CSIC (CIDoM) de la Universidad de Castilla-La Mancha
}

\author{
The Centro de Investigación y Documentación Musical-Unidad Asociada al \\ CSIC (CIDoM) of University of Castilla-La Mancha
}

\author{
Paulino Capdepón \\ Universidad de Castilla-La Mancha \\ paulino.capdepon@uclm.es \\ Juan José Pastor \\ Universidad de Castilla-La Mancha \\ juanjose.pastor@uclm.es
}

\section{RESUMEN}

Este artículo se centra en la fundación y evolución del Centro de Investigación y Documentación Musical de la Universidad de Castilla-La Mancha como iniciativa del Grupo de investigación reconocido "Patrimonio musical de Castilla-La Mancha" hasta su reconocimiento como Unidad Asociada al CSIC en 2015. Asimismo se tienen en cuenta los objetivos del mencionado Centro así como las actividades desarrolladas en el ámbito de la organización de congresos, jornadas, seminarios; de la publicación de monografías en tres colecciones editoriales y un sello discográfico; o bien en el terreno de la investigación llevada a cano hasta el presente.

Palabras clave: UCLM, Investigación, Documentación musical, Unidad Asociada, CSIC, Congresos, Publicaciones, Colección editorial, Sello discográfico.

\section{Abstract}

This paper focuses on the founding and evolution of the Centro de Investigación y Documentación Musical (Music Research and Documentation Center) of University of Castilla-La Mancha as an initiative of the research group "Musical Heritage of Castilla-La Mancha" recognized as Associated Unit to the CSIC in 2015. It also takes into account the objectives of the mentioned Center, as well as the activities carried out in the field of the organization of congresses, conferences, seminars; the publication of monographs in three publishing collections and a record label; or in the field of researching carried out up to the present. 


\section{EL CENTRO DE INVESTIGACIÓN Y DOCUMENTACIÓN MUSICAL- UNIDAD ASOCIADA AL CSIC (CIDOM) DE LA UNIVERSIDAD DE CASTILLA-LA MANCHA}

Key words: UCLM, Researching, Musical Documentation, Associated Unit, CSIC, Conferences, Publishings, Publishing Collection, Record Label.

Capdepón Verdú, P.; Pastor Verdú, J. J. (2016). El Centro de Investigación y Documentación Musical- Unidad Asociada al CSIC (CIDoM) de la Universidad de Castilla-La Mancha. Cuadernos de Investigación Musical, 1, 78-92.

\section{INTRODUCCIÓN}

La recuperación y difusión del patrimonio musical ha constituido una de las preocupaciones principales de la musicología española en los últimos treinta años, consecuencia de lo cual fue la fundación de un buen número de centros de investigación o de documentación musical en toda la geografía española. En la comunidad castellanomanchega, un primer paso fue la creación del Grupo reconocido de investigación "Patrimonio musical de Castilla-La Mancha" en 2009, que a día de hoy está formado por 12 investigadores de los cuatro campus que conforman la Universidad de Castilla-La Mancha.

\section{LOS ORÍGENES}

Deseando el Grupo de investigación antes citado dar un paso más en la consolidación de la investigación musical en la UCLM y en la región, se decidió presentar una solicitud de creación de un centro propio de investigación en el seno de la Facultad de Letras, siendo aprobado el 6 de junio de 2012 en la Junta de la mencionada Facultad, sita en Ciudad Real, a instancias de los profesores Titulares de Universidad Paulino Capdepón y Juan José Pastor, y contando con una Secretaría Académica coordinada por el también profesor Titular de Universidad José Luis de la Fuente así como con un equipo formado por los profesores Titulares de Universidad Antonio Alcázar, María del Valle de Moya y Felipe Gértrudix. Todos los miembros del centro pertenecían al Departamento de Didáctica de la Expresión Musical, Plástica y Corporal de la UCLM.

Coincidiendo con la presentación oficial del CIDoM en noviembre de 2012 se celebraron en la Facultad de Letras de Ciudad Real las I Jornadas de Investigación y Patrimonio Musical de Castilla-La Mancha, reunión en la que se dieron cita una docena de musicólogos que expusieron las diferentes líneas de investigación que se desarrollan en nuestra comunidad, algunas estrechamente vinculadas al patrimonio musical de Castilla-La Mancha. 
PAULINO CAPDEPÓn y JUAN JOSÉ PASTOR

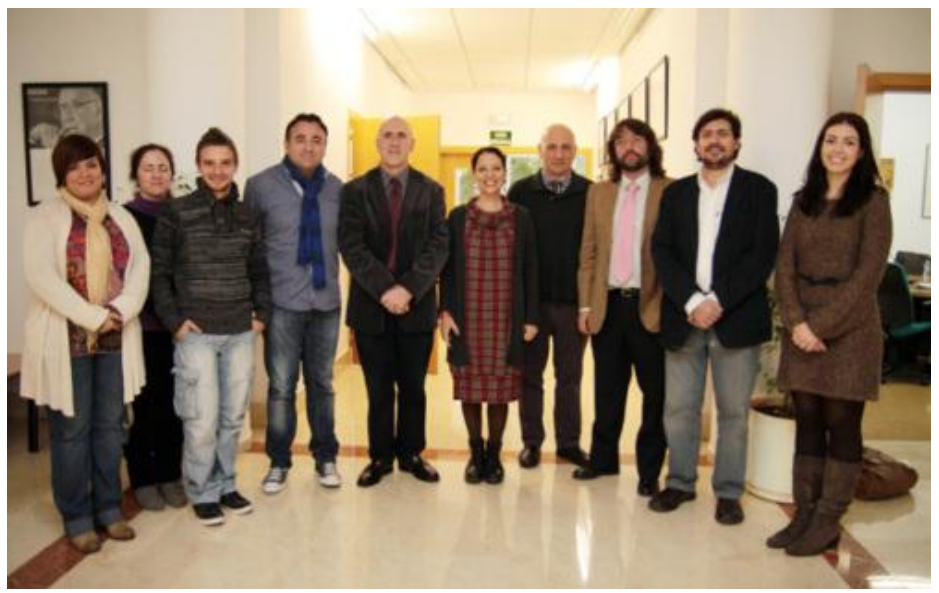

Fig. 1. Miembros del CIDoM (21 de noviembre de 2012)

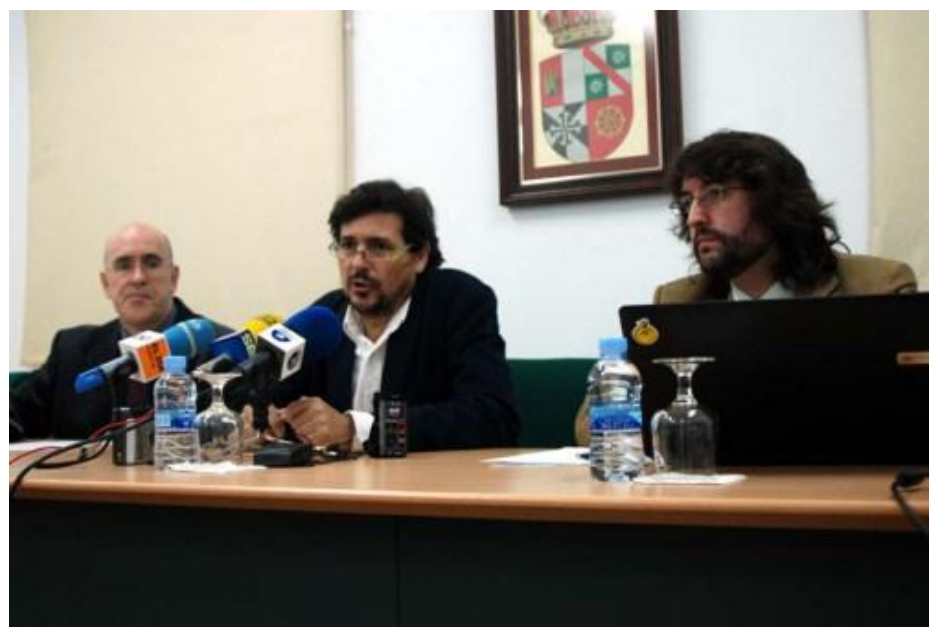

Fig. 2. Presentación oficial del CIDoM a la prensa (21 de noviembre de 2012)

En esta línea se escucharon las propuestas de Francisco López sobre el valor documental y musicológico de los fondos de ópera del Museo Nacional del Teatro en Almagro; el trabajo de Lucía Donoso sobre el compositor criptanense Ángel Arteaga (1928-1984); la exposición de Octavio Peidró sobre el compositor originario de La Solana Tomás Barrera (1870-1938), el análisis de Vicente Castellanos sobre el legado históricomusical de Salomón Buitrago en la catedral de Ciudad Real, o el estudio de Elisa Colino sobre los programas de educación bilingüe en la región proyectados sobre el área de Música. Junto a estas propuestas se presentaron otras fijadas en la Edad de Plata española, tales como el homenaje musical a Góngora en su tercer centenario, analizado por Said Ruiz o la reflexión de Marta Nieto sobre el escritor y crítico musical Vicente Salas Viu (19111967), exiliado en Chile. Con un pie ya en Hispanoamérica, los asistentes atendieron a las contribuciones de Silvia Fernández en torno a Cecilia Valdés y su importancia en la definición del género de la zarzuela cubana o la de Carmela Fischer sobre la ópera María de Buenos Aires de Astor Piazzolla. Las ponencias y comunicaciones presentadas a estas 
EL CENTRO DE INVESTIGACIÓN Y DOCUMENTACIÓN MUSICAL-UNIDAD ASOCIADA AL CSIC (CIDOM) DE LA UNIVERSIDAD DE CASTILLA-LA MANCHA

Jornadas dio lugar a la publicación de una monografía bajo el título de El patrimonio musical de Castilla-La Mancha: nuevas perspectivas, publicado por la editorial Alpuerto en 2016.

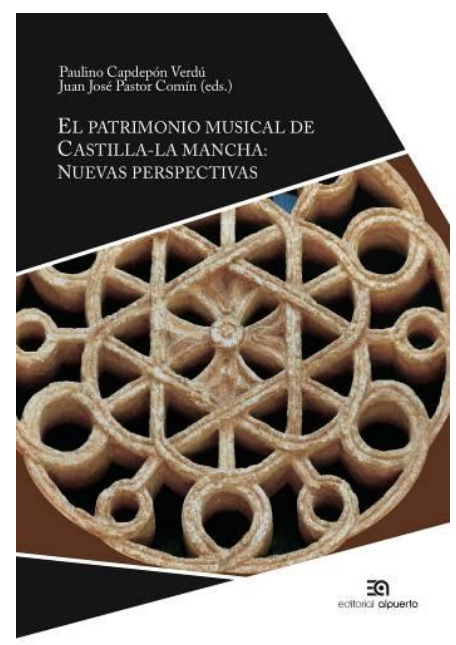

Fig. 3. El patrimonio musical de Castilla-La Mancha... (2016)

\section{LA COLECCIÓN BIBLIOTECA DE INVESTIGACIÓN Y PATRIMONIO MUSICAL}

Un año después de la presentación del CIDoM, en 2013 se daba a conocer la primera colección de musicología fundada por nuestro Centro bajo el título de Biblioteca de Investigación y Patrimonio Musical, como fruto del acuerdo entre el CIDoM y la Editorial Academia del Hispanismo y fundada por los profesores de la UCLM Juan José Pastor y Paulino Capdepón.

En 2011 se publicó el primer volumen de la colección Biblioteca de Investigación y Documentación Musical": se trataba de un novedoso estudio dedicado a la Sociedad Filarmónica de Madrid ${ }^{1}$, a cargo del catedrático de la Universidad de Salamanca y relevante compositor, José María García Laborda. El impacto de tal estudio fue tal que se alzó unánimemente con el "Premio Menéndez Pelayo de Investigación Humanística" 2012, concedido en febrero de 2013 por la Real Sociedad Menéndez Pelayo².

\footnotetext{
1 Véase http://www.academiaeditorial.com/web/colecciones/musical/la-sociedad-filarmonica-de-madrid1901-1936/

2 Véase http:/ / agencias.abc.es/agencias/noticia.asp?noticia=1362465.

Cuadernos de Investigación Musical, 2016, diciembre, no 1, págs. 78-92.

ISSN: $2530-6847$
}

DOI: dx.doi.org/10.18239/invesmusic_2016.01.1310 


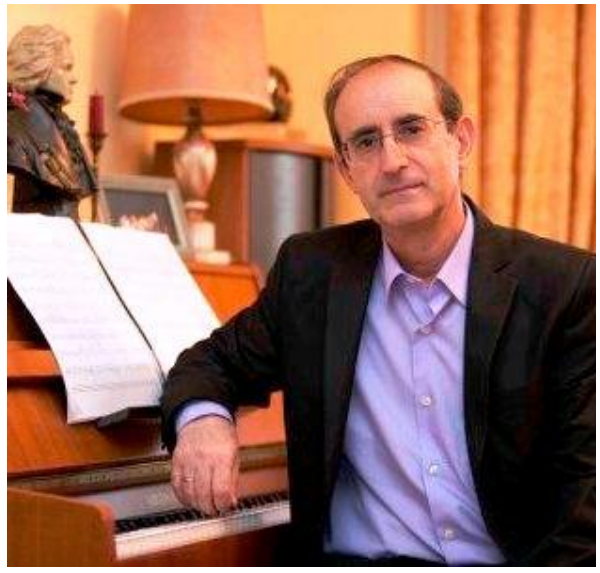

Fig. 4. José María García Laborda

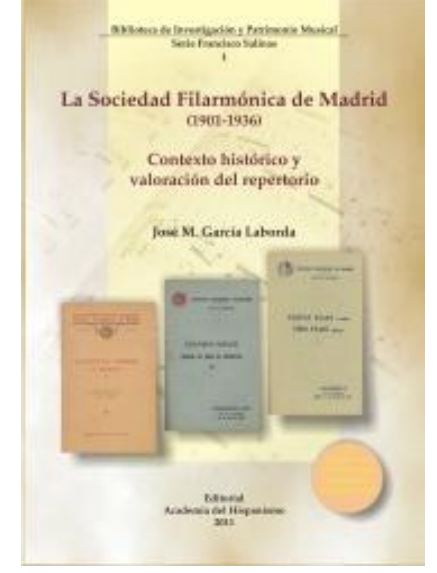

Fig. 5. La Sociedad Filarmónica de

Madrid... (2011)

Por otra parte, en 2013 fue dado a conocer el segundo volumen de la mencionada colección, relacionado directamente con la recuperación y difusión del extraordinario patrimonio musical que atesora nuestra comunidad de Castilla-La Mancha. En este caso, 16 profesores e investigadores procedentes de universidades españolas, europeas y norteamericanas de relieve internacional colaboraron bajo la coordinación de los profesores Capdepón y Pastor en la preparación de una gran monografía sobre el compositor Sebastián Durón, nacido en Brihuega (Guadalajara) en 1660. Con ello la UCLM quería rendir homenaje al que posiblemente haya sido uno de los más destacados compositores que ha dado la región ya que llegó a alcanzar dos de los puestos musicales más prestigiosos en la España del Barroco: organista y maestro de la Real Capilla de Madrid, donde desarrolló una extraordinaria carrera compositiva tanto en el ámbito de la música sacra como en el de la música profana, llegando a convertirse en uno de los referentes del teatro musical de su tiempo gracias a sus óperas y zarzuelas, varias de las cuales han sido rescatadas y editadas por el catedrático de la Universidad de Granada, Antonio Martín Moreno, quien precisamente escribió el artículo inicial de la monografía que se dio entonces a conocer en la Biblioteca de Investigación y Documentación Musical.

\section{RECONOCIMIENTO COMO UNIDAD ASOCIADA ${ }^{3}$}

En agosto de 2015 tuvo lugar la firma del convenio por el que se aprobaba la creación del Centro de Investigación y Documentación Musical (UCLM). Unidad asociada al CSIC. Fueron el rector de la Universidad de Castilla-La Mancha, Miguel Ángel Collado y el Vicepresidente del CSIC, José Ramón Urquijo, los signatarios de dicho convenio.

La asociación entre el Centro de Investigación y Documentación Musical (UCLM). Unidad asociada al CSIC y el Grupo de investigación "Patrimonio histórico español" de la Institución Milá i Fontanals del CSIC (dirigido por los investigadores del CSIC Antonio Ezquerro Esteban y Luis Antonio González Marín) fue establecida en 2015 con el fin principal de impulsar toda una serie de actividades encaminadas a la recuperación,

\footnotetext{
3 Véase http://www.uclmtv.uclm.es/el-csic-reconoce-como-unidad-asociada-al-centro-de-investigacion-y-
} documentacion-musical-de-la-uclm/ 


\section{EL CENTRO DE INVESTIGACIÓN Y DOCUMENTACIÓN MUSICAL- UNIDAD ASOCIADA AL CSIC (CIDOM) DE LA UNIVERSIDAD DE CASTILLA-LA MANCHA}

conservación, estudio, difusión y publicación (en formato impreso, digital y audiovisual) del patrimonio musical de España. Para ello se han articulado una serie de estrategias y actuaciones que estarán relacionadas fundamentalmente con la investigación, entre las que se incluyen la organización y celebración de congresos y jornadas científicas para dar a conocer los logros y resultados de la asociación, la presentación conjunta a convocatorias de investigación nacionales y europeas, la publicación de monografías de interés común sobre el patrimonio musical español, la catalogación de fuentes musicales que aun han permanecido inéditas en España, el estudio de la conservación de las fuentes musicales en sus distintos soportes y la digitalización de dichas fuentes, la grabación sonora del repertorio musical recuperado gracias a la asociación o el apoyo mutuo en la impartición de cursos, seminarios y másteres, tanto en la Universidad de Castilla-La Mancha como en el CSIC.

En otro orden de cosas, la asociación trata de fomentar el estudio de las fuentes musicales históricas de España tanto desde las áreas específicamente musicológicas como desde un acercamiento interdisciplinar (Historia del Arte, Filosofía, Filologías, Sociología, etc...) desde un acercamiento interdisciplinar al patrimonio musical.

Sin duda alguna, la asociación entre las dos entidades fortalecerá y cohesionará la investigación musical en España, en un momento en que se está otorgando singular importancia a todos los aspectos relacionados con la conservación del patrimonio cultural y artístico en general y del musical en particular.

\section{OBJETIVOS}

Entre los principales objetivos que han justificado la presencia del CIDOM, caben destacar los siguientes:

1. Cubrir el enorme vacío existente en la región en lo que concierne a la falta de una institución responsable de la investigación y documentación musical. En este sentido CIDoM se presenta como una propuesta cualificada capaz de desempeñar sus responsabilidades en las direcciones propuestas por la International Association of Music Libraries, Archives and Documentation Centres (IALM), la Asociación Española de Documentación Musical (AEDOM), la Sociedad Española de Musicología (SEDEM) y el Instituto Nacional de Artes Escénicas y Música (INAEM), siguiendo los estándares de calidad y criterios de documentación e investigación sancionado por dichas instituciones a las que los miembros del Centro pertenecen.

2. Potenciar, a través de la investigación musicológica, las relaciones transversales entre Universidad, administración regional, provincial y local, la comunidad de intérpretes y profesionales del sector profesional de la música, así como de la comunidad musical educativa. En este sentido el CIDoM. Unidad Asociada al CSIC se propone como una herramienta esencial en el trabajo orgánico de los distintos sectores dedicados a la actividad musical, propiciando no sólo fuentes para la interpretación y divulgación del patrimonio, sino también los criterios científicos y académicos para guiar la actividad musical, 


\section{PAULINO CAPDEPÓN y JUAN JOSÉ PASTOR}

facilitando así dictámenes, estudios, programas y análisis que permitan generar una programación musical formada y formadora, coherente, didáctica y de valor musicológico capaz de generar un valor añadido en el turismo cultural de la región.

3. Iniciar el trabajo de documentación sistemática del patrimonio musical de la región, poco conocido y escasamente estudiado. Esta tarea esencial ha de permitir, por un lado, el análisis y estudio de las obras de los compositores fundamentales de nuestra región reconocidos por la musicología internacional pertenecientes a distintas épocas, tales como Diego Ortiz, Sebastián de Covarrubias, Alonso Xuárez, Torrejón y Velasco, Sebastián Durón, Tomás Barrera, Ángel Arteaga, Manuel Ángulo, Valentín Bielsa, etc... Por otro, ordenar, clasificar y catalogar las fuentes de información y obra musical ignorada y contenida en los distintos archivos catedralicios y administrativos de la región, con el fin de reconstruir la historia musical de los distintos centros musicales en la región que fueron sin duda importantes en distintas épocas (Toledo, Sigüenza, Talavera de la Reina, Cuenca, Guadalajara, Pastrana, etc...) y facilitar a la comunidad de profesionales la edición y estudio de tales obras para su estreno y programación, contribuyendo a la especificidad y excelencias de importantes festivales de la comunidad autónoma.

4. Proyectar los resultados de la investigación en el área de Didáctica de la Expresión Musical sobre el conjunto de la comunidad educativa - profesional y general-, procurando así un lugar de referencia que permita la creación e implementación de herramientas educativas demandadas por el profesorado con el fin de incrementar la calidad y las relaciones transversales de la educación musical en los distintos niveles educativo.

5. Dotar a la administración regional de una serie de respuestas coordinadas y formadas ante las necesidades formativas demandas por su profesorado, facilitando el asesoramiento de un consejo consultivo de carácter internacional, y poniendo a su disposición los recursos científicos y académicos del CIDoM, con el fin de satisfacer las demandas de formación continua en los profesionales de la educación musical.

6. Potenciar la investigación de carácter interdisciplinar que ponga en contacto los estudios específicos de naturaleza musical con materias colindantes, esenciales y necesarias en el estudio musicológico pertinente, y que desvelan aspectos muy significativos desde sus propios paradigmas disciplinares: las relaciones entre la música y otras artes (literatura, pintura, teatro, etc.), factores sociológicos, iconográficos, análisis de género, estudios culturales, políticos y metodológicos bajo cuya perspectiva es necesario el examen y análisis del patrimonio musical.

7. Dinamizar el sector educativo, documental y cultural de la región a través de la investigación buscando cauces para la participación en la misma de los profesionales interesados en ella. En este sentido es importante vertebrar a través de la investigación musicológica no sólo el ámbito de la programación cultural, sino su relación como realidad vivida con el sector educativo, beneficiario primero de un auténtico interés por el patrimonio musical de la región. 
EL CENTRO DE INVESTIGACIÓN Y DOCUMENTACIÓN MUSICAL-UNIDAD ASOCIADA AL CSIC (CIDOM) DE LA UNIVERSIDAD DE CASTILla-LA MANCHA

\section{LÍNEAS TEMÁTICAS PRINCIPALES}

\subsection{PATRIMONIO MUSICAL HISTÓRICO}

Consciente de la necesidad de una eficaz transferencia del conocimiento, el CIDoM mantiene una intensa actividad editorial con dos de las más prestigiosas editoriales de nuestro país: Academia del Hispanismo y Alpuerto. Esta actividad ha propiciado trabajos colectivos en torno al músico barroco de Brihuega Sebastián Durón (1660-1716), sobre el patrimonio musical de Castilla-La Mancha, así como en torno a la presencia de Mozart en España. Deben destacarse igualmente los diferentes volúmenes que constituyen la opera omnia del maestro de capilla conquense Alonso Xuárez (1640-1696) a cargo de José Luis de la Fuente; los estudios sobre la capilla musical de La Colegial en Talavera de la Reina, realizados por Paulino Capdepón (XX Premio de Historia Fernando Jiménez. de Gregorio); las diferentes publicaciones sobre la recepción musical cervantina y de otros poetas del Siglo de Oro, de Juan José Pastor; los análisis de Felipe Gértrudix sobre El libro de música de vibuela de Diego Pisador (ca. 1509 - ca. 1557), o el estudio de Javier Moreno sobre los villancicos de la Catedral de Toledo en el siglo XVIII, trabajos que constituyen algunas de las más sobresalientes aportaciones del CIDoM al patrimonio musical de la región. Junto a los ya citados, son especialmente significativos los estudios sobre el asociacionismo musical en Castilla-La Mancha, de María del Valle de Moya, así como los realizados por Antonio Alcázar, tanto en el ámbito del análisis perceptivo de las músicas electroacústicas como en el del desarrollo de recursos, materiales y estrategias didácticas alrededor de la creación sonora, músicas experimentales y medios electroacústicos, siendo uno de los máximos conocedores en España del histórico Gabinete de Música Electroacústica de Cuenca.

\subsection{EDUCACIÓN MUSICAL}

La mayoría de los integrantes del CIDoM han sido antes funcionarios de carrera en etapas educativas previas a la Universidad, hecho que justifica su preocupación por el ámbito de la Educación Musical, espacio en el que destacan los trabajos sobre Música y Nuevas Tecnologías desarrollados por el profesor Felipe Gértrudix; los de competencia emocional de la profesora María del Valle de Moya; los estudios de naturaleza interdisciplinar en el ámbito educativo sobre música y literatura del profesor Juan José Pastor; y aquellos otros sobre la Pedagogía de la Creación Musical del profesor Antonio Alcázar.

\subsection{MÚSICA Y LITERATURA}

Música y Literatura no han sido sino una sola realidad allí donde la palabra y su encarnadura sonora han conformado una única experiencia indisociable, íntima y social, articulada por el ritmo, el timbre, la intensidad, la duración y la textura del significante en consonancia-y también en disonancia- con el valor referencial y

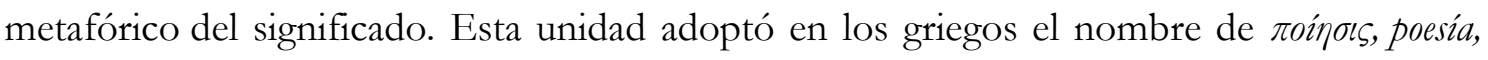




\section{PAULino CAPDEPÓn y JUAN JOSÉ PASTOR}

un acto de revelación -un nuevo "dar a luz" en el mundo- que extendería su naturaleza en las formas líricas, épicas y dramáticas.

La paulatina emancipación de cada uno de estos aspectos vinculados al hecho sonoro determinó, a lo largo de la historia, el crecimiento de una música más allá de la palabra y de una nueva escritura en apariencia independiente de todo contexto cadencial y, en definitiva, musical. Sin embargo, no solo la existencia de un amplio espacio patrimonial en el que Música y Literatura aparecen conjuntamente, sino la constante y recíproca apelación que, de la mano de diferentes autores y compositores, una y otra hacen de aquella primera marca genética a través de las formas, estructuras, ritmos, medidas, así como del contexto social que comparten, constituyen pruebas innegables de una participación mutua que ambas artes, como disciplinas en la academia, han preferido siempre dejar en un espacio residual. Sirva, pues, este proyecto para reunir desde los márgenes esta plural forma de ser y sus muy distintas formas de convivencia en lengua española, y así reconstruir en el tiempo los caminos que el hecho musical y literario transitaron juntos y en los que, como dos buenos compañeros de viaje, iluminaron el uno al otro sus pasos.

Uno de los principales proyectos que se desarrollará en este ámbito será el proyecto de naturaleza digital Las música de Cervantes en torno a dos aspectos fundamentales de la obra cervantina:

1. Por un lado, el estudio de la realidad musical que nuestro escritor incorpora en el conjunto de sus textos y analizar su valor, dimensión y repercusión en el ámbito de la significación literaria. Esta presencia adopta una forma diversa manifestada en numerosos instrumentos musicales; canciones citadas, cantadas, representadas o embebidas; bailes y danzas; así como un sin fin de juicios y valoraciones que afectan al contexto musical vivido por nuestro autor y que lo convierten en un valioso testimonio musicológico.

2. Por otro lado, atenderemos a ese otro aspecto que podemos denominar la recepción musical del hecho literario. Conocemos bien las formas de pervivencia de una obra literaria en el ámbito editorial, así como su influencia y procesos de cita y reescritura en otros poetas, dramaturgos o narradores. Sin embargo conocemos menos de qué modo una obra literaria es interpretada a través del lenguaje musical y cómo esa nueva composición emerge como lectura crítica y creadora de un texto precedente, al tiempo que se instala como una nueva representación artística en un contexto social dado.

Este proyecto, cuya gestación extiende sus raíces a la tesis doctoral de Juan José Pastor Música y Literatura: la senda retórica. Nuevos materiales para el análisis de la música en Cervantes y el estudio de la recepción musical de su obra (Universidad de Castilla-La Mancha, 2004), nace con una vocación didáctica que desea presentar con objetividad los distintos materiales -textos, explicaciones, imágenes, archivos de audio, etc.- tanto al primer lector que se aproxime a Cervantes sin grandes alforjas cargadas de prejuicios, como al lector filólogo, historiador de la literatura, teórico literario o musicólogo, advertido cada cual de la 


\section{EL CENTRO DE INVESTIGACIÓN Y DOCUMENTACIÓN MUSICAL- UNIDAD ASOCIADA AL CSIC (CIDOM) DE LA UNIVERSIDAD DE CASTILLA-LA MANCHA}

naturaleza de cuanto busca y de su exclusivo prisma deformador y profesional. Sirva, pues, esta contribución para saldar en Cervantes una deuda académica y metodológica que nuestros colegas del ámbito anglosajón ya resolvieron con Shakespeare, Joyce o Dickens.

\section{La CElebración Del Congreso InTERnaCional sobre Cervantes y LA MÚSICA}

En septiembre de 2016 y al abrigo de la conmemoración cervantina, el CIDoM. Unidad Asociada al CSIC organizó un congreso internacional que fue declarado de "Alto Nivel" por el Ministerio de Economía y Competitividad ${ }^{5}$ y como tal, subvencionado por dicho organismo gubernamental. El título del Congreso fue Las músicas de Cervantes: del patrimonio bistórico a su recepción musical (s. XVI-XXI).

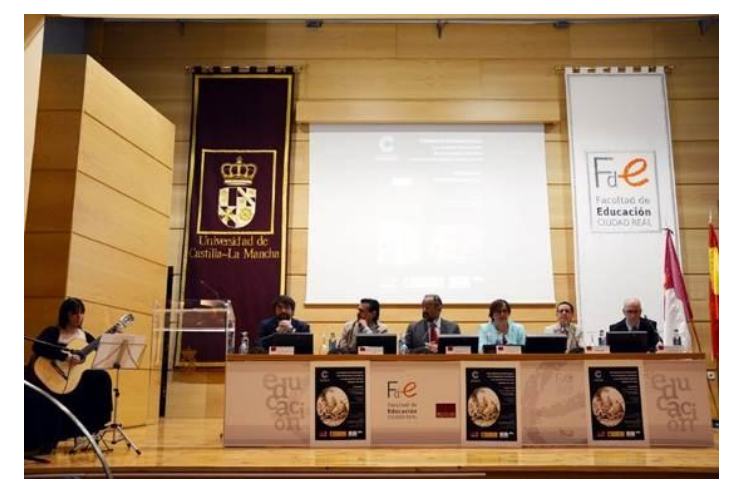

Fig. 6. Inauguración del Congreso internacional Las músicas de Cervantes

La conmemoración el año 2016 del centenario de la muerte de Cervantes constituía el momento oportuno para debatir no sólo cómo nuestro autor transformó su realidad coetánea musical en un elemento significante dentro de su obra, sino cómo fueron interpretados sus textos en obras musicales de temática cervantina que ahora constituyen un importante corpus de recepción crítica y hermenéutica dentro de nuestro patrimonio musical. Dos fueron los aspectos básicos que se discutieron en este congreso:

\subsection{PATRIMONIO MUSiCAL HistÓRICO}

La presencia en Cervantes de innumerables citas a canciones, romances, villancicos, danzas o bailes nos obliga a reflexionar sobre esta realidad presente en la España del XVI y principios del XVII. Se propone un encuentro para discutir la producción musical (vocal e instrumental) coetánea a Cervantes, tanto civil como religiosa, presente en el folklore tradicional o vigente en el cancionero sefardí, así como depositada en los archivos históricos eclesiásticos y bibliotecas nobiliarias, y referenciada en la documentación civil y

\footnotetext{
4 Véase http://www.oretania.es/2016/09/21/la-uclm-celebra-a-miguel-de-cervantes-desde-la-vertientemusical/

${ }^{5}$ Ministerio de Economía y Competitividad. Acción I+D Congresos de Alto Nivel. Referencia HAR201563153-CIN. Investigador Principal: Juan José Pastor Comín.

Cuadernos de Investigación Musical, 2016, diciembre, nº 1, págs. 78-92.

ISSN: 2530-6847
}

DOI: dx.doi.org/10.18239/invesmusic_2016.01.1310 


\section{PAULINO CAPDEPÓN y JUAN JOSÉ PASTOR}

en los testimonios históricos, políticos, filológicos, poéticos, iconográficos y religiosos que amplifican esa realidad musical vivida y transformada por Cervantes. Este examen nos permitirá profundizar en los sentidos y usos que dichos elementos tenían en su momento y así valorar su adecuada interpretación en el interior de sus textos.

\subsection{RECEPCIÓN MUSICAL}

Estudiaremos la presencia de los textos cervantinos en espectáculos musicales, hecho que nos sitúa ante una recepción musical plural y prolífica que se extiende desde principios del XVII hasta el siglo XXI en una amplia diversidad de géneros -desde el villancico a la ópera, pasando por la canción de concierto, música para narrador y orquesta o banda sonora cinematográfica, etc.- ${ }^{-}$, prestando igualmente especial atención a la creación contemporánea que se ha servido de la obra cervantina para contribuir al crecimiento del patrimonio musical de nuestro país.

Por otra parte, los bloque temáticos del Congreso fueron los siguientes:

1. Por un lado, el valor de la realidad musical intencionalizada en sus textos y su valor semántico explorando el patrimonio musical a él coetáneo y discutiendo la verdadera naturaleza del hecho musical incorporado al discurso literario y analizando sus implicaciones no solo ya como testimonios del contexto musical de finales del XVI y principios del XVII - con la heredad renacentista como contexto irrenunciable-, sino como herramienta para una interpretación coherente que nos ayude a desvelar las intenciones y sentidos contenidos en la escritura cervantina. De singular relevancia será la comparación del hecho musical en Cervantes con los estudios realizados en el mismo sentido y mucho más avanzados sobre la figura de William Shakespeare. En este sentido se propuso el debate sobre los siguientes aspectos:

- Fuentes históricas sobre la realidad musical en la familia Cervantes (documentos notariales y civiles, contratos, cláusulas testamentarias, relaciones de fiestas y espectáculos, etc...).

- Realidad organológica cervantina y valores sociales y simbólicos, así como otros usos en escritores coetáneos.

- Dimensión religiosa y parodia de los referentes musicales tanto en Cervantes como en la literatura de su tiempo.

- Canciones, villancicos y romances embebidos en los textos cervantinos y en las fuentes literarias coetáneas: fuentes históricas, orales y función textual.

- Músicas de influencia italiana presentes en contextos pastorales cervantinos y otros usos musicales en la literatura de su tiempo.

- Contrafacta de sonetos y poemas de poetas precedentes: difusión a través de la música de vihuela (Garcilaso o Cetina en las obras de Mudarra, Valderrábano, Narváez, etc.) y presencia en la lírica, novela y teatro áureo. 


\section{El CENTRO DE INVESTIGACIÓN Y DOCUMENTACIÓN MUSICAL- UNIDAD ASOCIADA AL CSIC (CIDOM) DE LA UNIVERSIDAD DE CASTILLA-LA MANCHA}

- Bailes y danzas en Cervantes y en su tiempo: tratadística, tradición y pervivencia. - La voz como instrumento en el teatro y la novela aurisecular. Tratados de canto y valor simbólico.

- El romancero sefardí y su presencia no solo en los textos cervantinos, sino también entre los escritores coetáneos: música del exilio.

- Pensamiento teórico musical en la época de Cervantes y su reflejo en sus textos.

- Lectura en alta voz: referentes musicales en las novelas y textos dispuestos para ser cantados. Inserción de la lírica en la narrativa en los textos del Siglo de Oro.

- Imágenes emblemáticas musicales presentes en Cervantes. Antecedentes, análisis y proyección en la literatura áurea.

- Iconografía musical y representación escénica. Representaciones pictóricas y marcos de sentido.

- Paremiología y voces musicales. El valor del Tesoro de la Lengua de Covarrubias, coetáneo de Cervantes.

- Tipos y profesiones vinculados al hecho musical tanto sobre la escena teatral como en las novelas cervantinas.

2. Por otro lado, se dedicaron tres sesiones de comunicaciones a examinar la recepción musical de la obra cervantina en la música española como ejercicios de interpretación literaria, examinando el patrimonio musical español atendiendo a una pluralidad de obras y géneros: ópera, zarzuela, música de cámara, para instrumento solo, banda, sinfónica, canción de concierto, narrador y orquesta, así como su presencia en músicas urbanas y contemporáneas.

Las actas del congreso serán publicadas en 2017 en nuestra colección Investigación y Patrimonio musical de la editorial Alpuerto.

\section{LAS PUBLICACIONES DEL CIDOM. UNIDAD ASOCIADA AL CSIC}

\subsection{COLECCIONES MUSICOLÓGICAS}

\subsubsection{Academia del Hispanismo: Biblioteca de Investigación y Patrimonio Musical}

La Biblioteca de Investigación y Patrimonio Musical de la Editorial Academia del Hispanismo aborda la edición de estudios musicológicos cuyo impacto es de índole nacional o internacional, bien por el tema desarrollado, bien por la naturaleza del compositor abordado. La colección destaca por alumbrar estudios que antes no han sido acometidos dentro del ámbito académico, y contribuir así al desarrollo de la musicología española desbrozando aspectos urgentes todavía pendientes. Sucede así con el primer monográfico dedicado a la Sociedad Filarmónica de Madrid, de José María García Laborda, cuyo funcionamiento impulsó la vida musical madrileña antes de la Guerra Civil y al que nos hemos referido anteriormente; el segundo volumen fue consagrado a Sebastián Durón; 


\section{PAULINO CAPDEPÓn y JUAN JOSÉ PASTOR}

y el tercero, publicado en 2016, a la recepción de Mozart en España, aspecto este, a pesar de su enorme interés, apenas examinado en la musicología española.

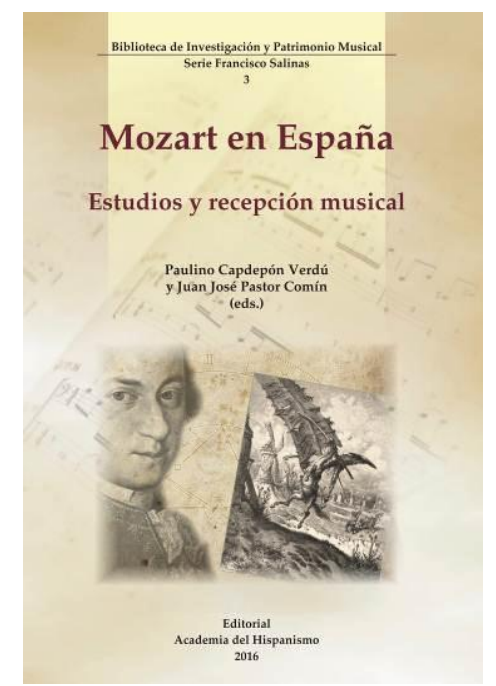

Fig. 7. Mozart en España... (2016)

\subsubsection{Editorial Alpuerto: Investigación y Patrimonio Musical}

En el año 2012, el CIDoM suscribió un convenio de colaboración con la editorial Alpuerto para crear la colección Investigación y Patrimonio Musical, cuyo objetivo principal es dar a conocer estudios relacionados con el ámbito de la recuperación del patrimonio histórico-musical en las distintas regiones del territorio nacional.

Aparecen así por primera vez en la musicología española nuevas visiones que permiten un mejor conocimiento y valoración de este extraordinario legado histórico perteneciente a centros eclesiásticos como Cuenca, Toledo y Talavera de la Reina o a centros civiles como el Museo Nacional del Teatro- pero sin olvidar la rica y variada realidad presente, atestiguada en la obra musical de autores como Barrera y Arteaga o en la mirada hacia la creación actual, gracias al libro ya citado El Patrimonio musical de Castilla-La Mancha: nuevas perspectivas o el nuevo volumen sobre patrimonio que está en proceso de edición.

Columna vertebral de esta colección es la edición de la opera omnia del insigne maestro castellano-manchego Alonso Xuárez, maestro de capilla de la catedral de Cuenca a cargo del profesor José Luis de la Fuente, que ha publicado hasta el momento tres volúmenes entre 2012 y 2015 y tiene en preparación varios volúmenes más sobre la obra del mencionado compositor y sobre la historia musical de la propia catedral de Cuenca. 


\section{EL CENTRO DE INVESTIGACIÓN Y DOCUMENTACIÓN MUSICAL- UNIDAD ASOCIADA AL CSIC (CIDOM) DE LA UNIVERSIDAD DE CASTILLA-LA MANCHA}

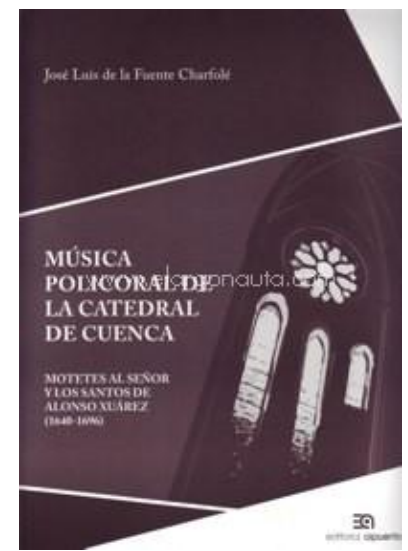

Fig. 8. vol. I de la opera omnia de A. Xuárez

(2012)

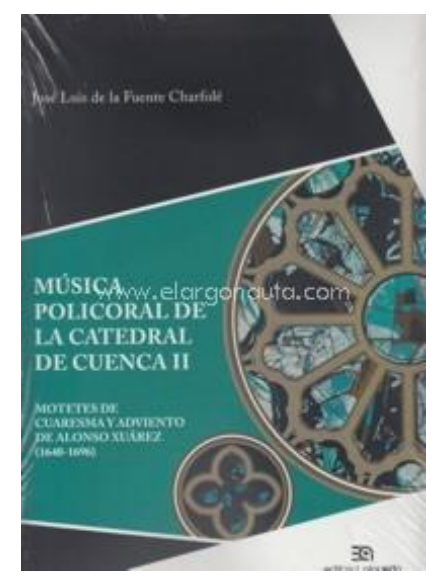

Fig. 9. vol. II de la opera omnia de A. Xuárez

(2013)

Sin embargo la colección Investigación y Patrimonio Musical no está limitada a la temática castellano-manchega, prueba de lo cual es la publicación del libro Música en imágenes: el maestro Nicolás Ledesma (1791-1883) en 2015, o el próximo libro sobre el maestro Andreví, ambos a cargo de Antonio Ezquerro y Gloria Ballús

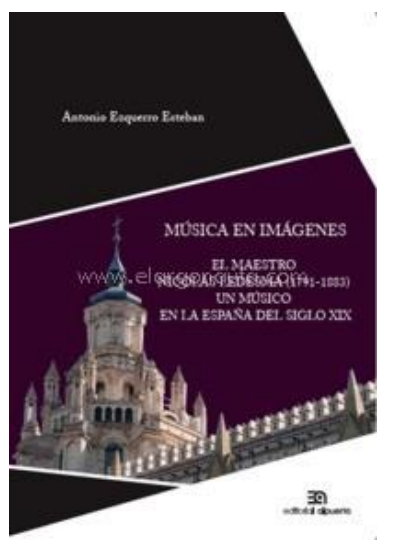

Fig. 10. Música en imágenes... (2015)

\subsubsection{Libros Mundi: Patrimonio musical de Castilla-La Mancha}

La colaboración del CIDoM con la Editorial Libros Mundi a través de la colección Patrimonio Musical de Castilla-La Mancha está centrada en la edición de estudios de carácter local orientados hacia la recuperación del patrimonio musical específico de la región. En este sentido acoge estudios vinculados al folklore y la oralidad, asociacionismo musical, así como a la recuperación de un vasto patrimonio vinculado a la música de banda, ámbito en el que queda todavía mucho por hacer. 


\section{PAULINO CAPDEPÓn y JUAN JOSÉ PASTOR}

Es así como con motivo del 150 aniversario de la creación de la Banda de Música de Almagro esta colección vio la luz con un estudio ejemplar de Francisco López Gómez, modelo sin duda para otros posteriores que aborden trabajos de similar naturaleza.

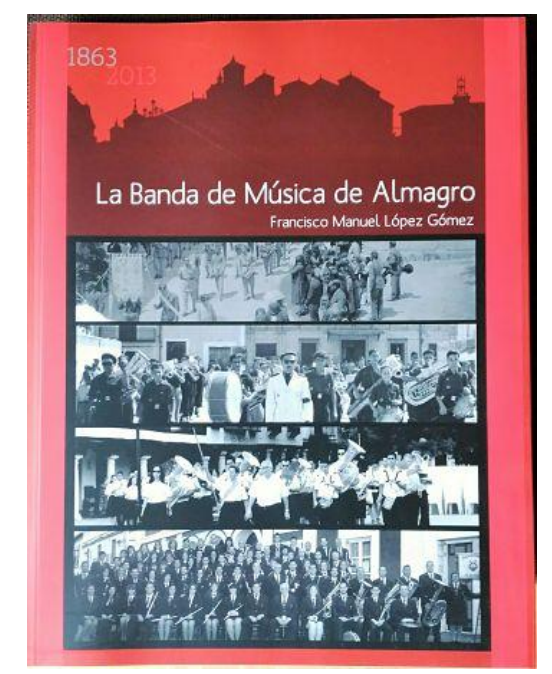

Fig. 11. La banda de música de Almagro (2014)

\subsection{SELLO DisCOGRÁfico LA FUGA DE ATALANTA}

La Fuga de Atalanta constituye el sello musical por excelencia del CIDoM, concebido para promover la proyección de jóvenes intérpretes y creadores a través de proyectos que abarquen la investigación histórica, musicológica, recuperación de fuentes, relaciones musicales y literarias, o revisiones idiomáticas en la lectura del patrimonio musical de naturaleza nacional e internacional, ofreciendo una nueva perspectiva sobre obras ya conocidas.

El primer volumen, que será dado a conocer en 2017, estará dedicado a la música de cámara de Wolfgang Amadeus Mozart.

Fecha de recepción: 30/10/2016

Fecha de aceptación: 15/12/2016 